\title{
ISOZYME PATTERN OF LEUKOCYTE $\alpha$-D-MANNOSIDASE IN PATIENTS WITH MANNOSIDOSIS
}

\author{
Hisaomi KawaI, Kenji Yoneda, Masanori Takeda, \\ Yoshihiko Nishida, Hiroshi Nishino, Kenjiro Masuda, \\ and Shiro SAITo \\ The First Department of Internal Medicine, School of Medicine, \\ The University of Tokushima, Kuramoto-3, \\ Tokushima 770, Japan
}

\begin{abstract}
Summary The isozyme patterns of leukocyte $\alpha$-D-mannosidase in two sisters with mannosidosis, their parents and a patient with trisomy 19 were studied. The isozyme pattern of liver mannosidase of a normal subject was also studied. In the patients with mannosidosis the neutral isozyme (isozyme $\mathrm{C}$ or fraction $\mathrm{C}$ ) was present, but the acidic isozymes (isozyme $\mathrm{A}$ and $\mathrm{B}$ or fraction $\mathrm{A}$ and $\mathrm{B}$ ) were not detectable. In their parents the activity of the acidic isozymes was one-third of the normal activity. These findings suggest that the patients are homozygous and their parents are heterozygous in terms of deficiency of acidic isozymes. In the patients with trisomy 19, the activity of $\alpha$-D-mannosidase was 4.9 times the upper limit of the normal value, while the levels of other lysozomal enzymes were normal. This increase was mainly due to increases of the $A$ and $B$ isozymes of mannosidase. This finding suggests that the gene encoding acidic isozymes, but not that encoding the neutral isozyme, is located on chromosome 19. The isozyme pattern of $\alpha$-D-mannosidase differed in different tissues of normal subjects, and the difference in severity of lesions in different organs of the patients with mannosidosis could be explained by differences in the isozyme patterns of the enzyme in these organs.
\end{abstract}

\section{INTRODUCTION}

Mannosidosis is a disorder caused by deficiency of the lysosomal enzyme $\alpha$-Dmannosidase. This enzyme has three isozymes coded by two distinct genes locates on different chromosomes.

We previously reported the clinical features and skeletal muscle pathology in

Received June 30, 1987; revised version received October 16, 1987; Accepted October 29, 1987 
two sisters with mannosidosis (Kawai et al., 1986). This paper reports the isozyme pattern of leukocyte $\alpha$-D-mannosidase in the patients and their parents in comparison with those in healthy controls and a patient with trisomy 19.

\section{MATERIALS AND METHODS}

The subjects examined were two sisters with mannosidosis (Kawai et al., 1985), their parents, and a patient ( 69 years old) with the myelodysplastic syndrome and trisomy 19. The proband of the family with mannosidosis, the 29-year-old younger sister of the two, had mental retardation and impaired hearing since childhood. At the age of 28 , she developed spastic gait and became unable to sit up or walk over a short period. The elder sister (36-year-old) is still ambulant but shows similar clinical manifestations. The mannosidase activity of leukocytes of both sisters were decreased remarkably (Kawai et al., 1985).

Peripheral blood leukocytes were isolated by the dextran gradient method of Kampine et al. (1966). Liver tissue was obtained at autopsy from a patient without liver disease to study the difference between the isozyme patterns in the liver and leukocytes. The isozyme pattern of $\alpha$-D-mannosidase in the leukocytes and liver were analyzed by electrophoresis and measurement of the $\mathrm{pH}$-dependence of the enzyme activity.

Samples of $\alpha$-D-mannosidase were prepared from the leukocytes and liver by the method of Schafit-Zagardo et al. (1980) and volumes of $3 \mu$ of each sample were subjected to electrophoresis on a cellulose acetate membrane (Fluharty et al., 1971).

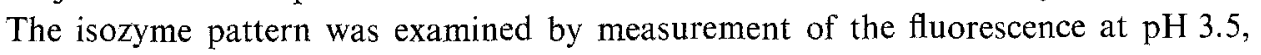
pH 4.5 and pH 6.5, as described by Poenau and Dreyfus (1973). Acidic isozymes $\mathrm{A}$ and $\mathrm{B}$ were detected at $\mathrm{pH} 3.5$ and 4.5 , respectively, and neutral isozyme $\mathrm{C}$ at $\mathrm{pH}$ 6.5 .

For study of the pH-dependence of the enzyme activity, the enzyme solution was prepared by the method of Hindman and Cotlier (1972) and its activity was assayed in the $\mathrm{pH}$ range of 3.0 to 7.1 . For measurement of the enzyme activity, a sample of $20 \mu \mathrm{l}$ of the enzyme solution was incubated with $100 \mu \mathrm{l}$ of 4 -methylumbelliferyl mannopyranoside as substrate, at $37^{\circ} \mathrm{C}$ for $1 \mathrm{hr}$. Then the reaction was stopped by addition of glycine- $\mathrm{NaOH}$ buffer, $\mathrm{pH} 10.4$, and the enzyme activity was calculated from the fluorescence intensity using 4-methylumbelliferone as a standard.

\section{RESULTS}

\section{1) Electrophoretic pattern of mannosidase isozymes}

Figure 1 shows the electrophoretic pattern of mannosidase isozymes of the leukocytes. In the healthy control, bands of isozyme $\mathrm{A}(\mathrm{pH} \mathrm{3.5)}$ and $\mathrm{B}(\mathrm{pH} 4.5)$ were observed, but the activity of isozyme $\mathrm{C}(\mathrm{pH} 6.5)$ was too low to detect. None of the isozymes were detectable in patient 1 with mannosidosis. The sample of the 


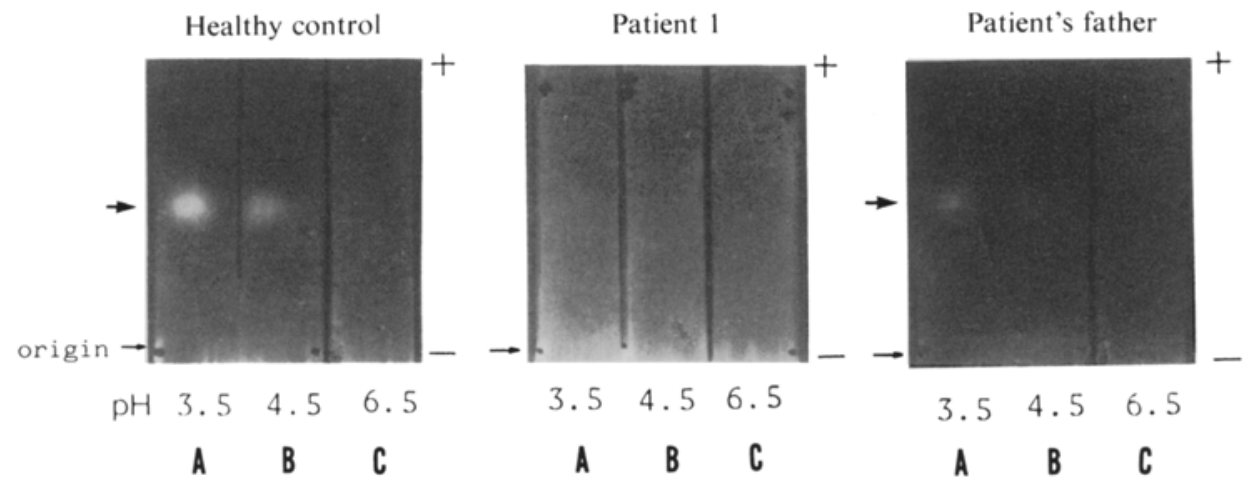

Fig. 1. Electrophoretic patterns of leukocyte $a-D$-mannosidase. Left, healthy control; middle, patient 1 with mannosidosis; right, her father.

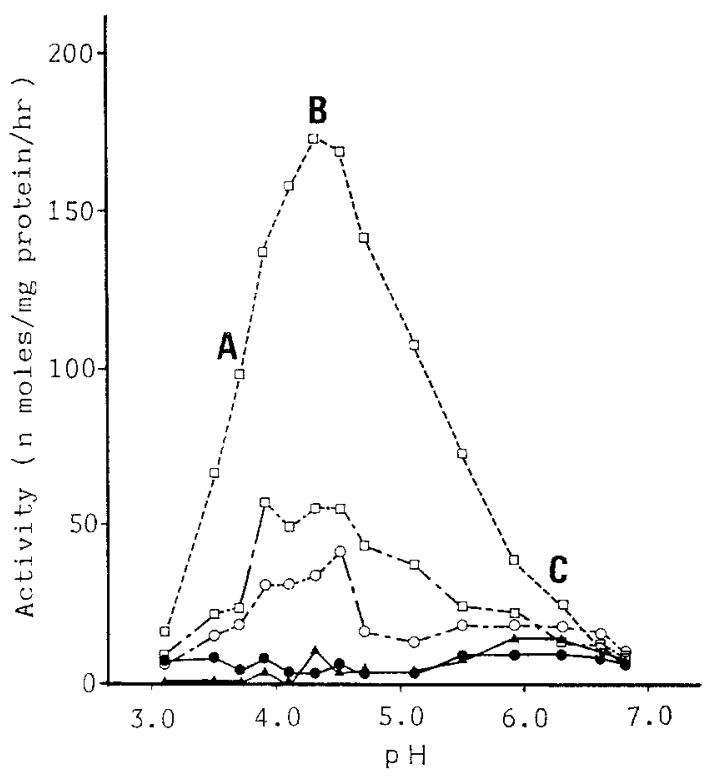

Fig. 2. pH-Dependence of $\alpha$-D-mannosidase activity of leukocytes of the two patients with mannosidosis, their parents and a healthy control. Patient $1(29 \mathrm{yr}, \mathrm{F}),-\mathbf{\Delta}-$; patient 2 (36yr, F). - - - ; father, - - $\square--$; mother, -- $\mathrm{O}--$; healthy control, $\cdots \square \cdots ; \mathrm{A}, \mathrm{pH} 3.5 ; \mathrm{B}, \mathrm{pH} 4.3 ; \mathrm{C}, \mathrm{pH} 6.5$.

father of the patients gave weaker bands of isozymes A and B than the healthy control and no isozyme $\mathrm{C}$ band as in the healthy control.

2) pH-Dependence of mannosidase activity of leukocytes from patients with mannosidosis and their parents

Figure 2 shows the pH-dependence of the mannosidase activities of leukocytes 
of the patients, their parents and a healthy control. In the control, the enzyme activities of fractions $\mathrm{A}$ and $\mathrm{B}$, observed at about the $\mathrm{pH}$ of 3.5 and 4.3 were higher than that of fraction $\mathrm{C}$ observed at about $\mathrm{pH} 6.5$. In contrast, the two patients with mannosidosis showed scarcely any activity in fraction $\mathrm{A}$ or $\mathrm{B}$, but the activity of fraction $\mathrm{C}$ was almost the same as that of the control. The activities of fractions $\mathrm{A}$

Table 1. Lysosomal enzyme activities of leukocyte from a patient with trisomy 19.

\begin{tabular}{lcc}
\hline Lysosomal enzyme & Enzyme activity & Normal range \\
\hline$\alpha$-Glucosidase & 21.4 & $11.2-49.0$ \\
$\alpha$-Galactosidase & 26.2 & $15.6-77.4$ \\
$\beta$-Galactosidase & 458 & $167-417$ \\
$\alpha$-Mannosidase & 876 & $35.0-178$ \\
$\alpha$-Fucosidase & 169 & $36.9-109$ \\
$\beta$-Glucuronidase & 124 & $26.5-130$ \\
\hline
\end{tabular}

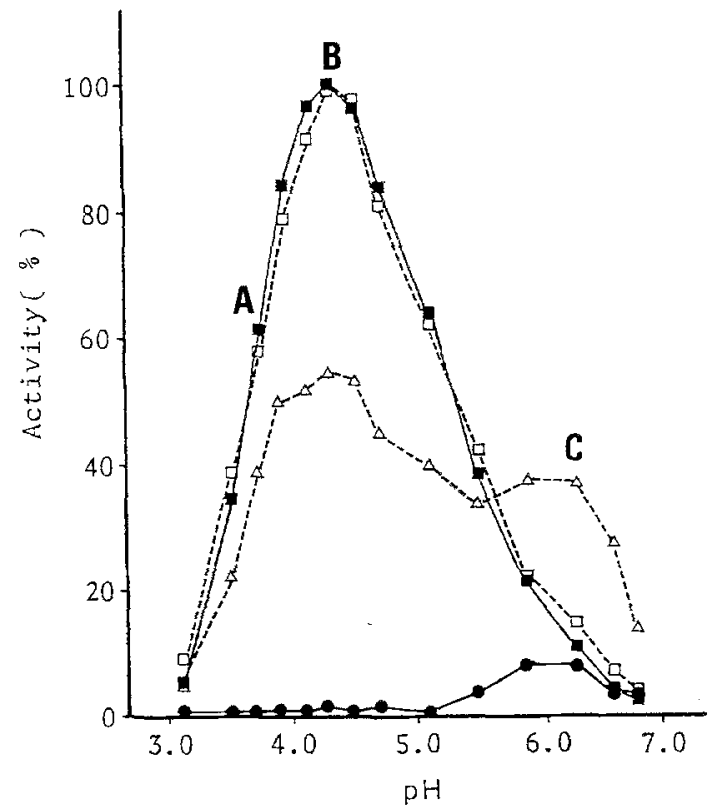

Fig. 3. pH-Dependence of $\alpha$-D-mannosidase activity in leukocytes and liver of a normal control and in leukocytes of a patient with trisomy 19 . To depict the $\mathrm{pH}$ dependency curve, the enzyme activity in leukocytes and the liver of the healthy control and in leukocytes of the patient with mannosidosis was expressed as the percentage of the maximum activity in leukocytes of healthy control whereas in leukocytes of the patient with trisomy 19 the maximum activity was calculated as $100 \%$. Leukocytes of a normal control, $\square$; liver of a normal control, $\Delta$; leukocyte of a patient with trisomy $19, \mathbf{E}$; leukocyte of a patient with mannosidosis (patient 2 ), - A, pH $3.5 ; \mathrm{B}, \mathrm{pH} 4.3 ; \mathrm{C}$, pH 6.5 . 
and $\mathrm{B}$ of the parents of the patients were about one-third of the control values, while the activity of their fraction $C$ was almost the same as that of the control.

\section{3) Lysosomal enzyme activity of leukocytes of a patient with trisomy 19}

Table 1 shows the activities of lysosomal enzymes in leukocytes from a patient with trisomy 19. The activities of all these enzymes, including $\alpha$-glucosidase, were within almost normal ranges, except that of $\alpha$-D-mannosidase, which was 4.9 times the upper limit of the normal range.

4) $p H$-Dependence of $\alpha$-D-mannosidase activity in leukocytes and liver of normal controls and in leukocytes of a patient with trisomy 19

Since the gene encoding the isozyme A or B of mannosidase is known to be located on chromosome 19 (Champion and Shows, 1977), the pH-dependent activity of the enzyme from the leukocytes and liver of normal controls and leukocytes of a patient with trisomy 19 were compared. The activity at each $\mathrm{pH}$ was calculated as a percentage of the maximum activity for leukocytes of a control and a patient with trisomy 19. As shown in Fig. 3, fractions A and B were predominant in the leukocytes from the control and the patient with trisomy 19, fraction C being very low in both. In contrast, the amounts of fractions A and B were less but that of fraction $\mathrm{C}$ was more in normal liver as compared with those in normal leukocytes.

\section{DUSCUSSION}

Mannosidosis is a metabolic disorder due to deficiency of the lysosomal enzyme $\alpha$-D-mannosidase (Öckerman, 1967). Case reports of mannosidosis in our country are very few; 3 cases from 2 families (Ichiki et al., 1981; Doi et al., 1982) and 2 cases in one family reported by us (Kawai et al., 1986). And no previous report described isozyme pattern of mannosidase. In this work, we examined the isozyme pattern of mannosidase in two patients with mannosidosis and in a patient with trisomy 19 in comparison with that in a healthy control.

On electrophoresis, leukocytes of two sisters, gave no detectable bands of isozymes $\mathrm{A}$ and $\mathrm{B}$, and leukocytes of the father of the patients showed reduced intensities of these bands. Analysis of the $\mathrm{pH}$ dependence of the enzyme activity revealed the absence of fractions $A$ and $B$, but the presence of fraction $C$ in the patients. In the parents, the amounts of fractions $\mathrm{A}$ and $\mathrm{B}$ were approximately one-third of the normal values.

The results reported by Poenau and Dreyfus (1973) suggest that isozymes A, B and $\mathrm{C}$ in the electrophoretic pattern correspond to fractions $\mathrm{A}, \mathrm{B}$ and $\mathrm{C}$ in the $\mathrm{pH}$ dependent curve. Moreover, isozymes $\mathrm{A}$ and $\mathrm{B}$, or fractions $\mathrm{A}$ and $\mathrm{B}$, are reported to be the products of the same gene (Cheng et al., 1986). Therefore, we conclude that our patients with mannosidosis are homozygous and that their parents are heterozygous for deficiency of fractions $\mathrm{A}$ and $\mathrm{B}$. 
Assay of the activities of various lysosomal enzymes, including mannosidase in leukocytes of a patient with trisomy 19 showed 4.9-fold increase in mannosidase activity. This increase could be explained by a gene dosage effect (Furgason-Smith and Aitken, 1978) due to trisomy, because one of the genes for $\alpha$-D-mannosidase is located on chromosome 19 (Ingram et al., 1977; Champion and Shows, 1977). Moreover, myelodysplastic syndrome per se may also have been involved in the abnormal increase of the enzyme activity. Studies on $\mathrm{pH}$-dependent enzyme activity demonstrated no detectable fraction $\mathrm{A}$ or $\mathrm{B}$ but the presence of fraction $\mathrm{C}$ in our patients with mannosidosis, indicating that the gene encoding fractions $\mathrm{A}$ and $\mathrm{B}$, and the gene encoding fraction $\mathrm{C}$, are located in different loci on a chromosome or on different chromosomes. Consistent with this result, Champion et al. (1978) reported that the gene for fraction $\mathrm{C}$ was located on chromosome 15. The mannosidase isozymes of the liver show a ratio of fraction $\mathrm{A}$ plus $\mathrm{B}$ to fraction $\mathrm{C}$ of approximately 6.5 to 3.5 , indicating that expression of fraction $C$ is greater in the liver than in leukocytes.

The two patients described in this paper were previously diagnosed as having type 2 mannosidosis (Kawai et al., 1986). They have hearing loss, mental retardation, hyperreflexia, motor ataxia and muscle weakness, but the lesions of their liver, kidneys and lungs are relatively mild. Thus, the extents of lesions vary considerably in different organs. Previous histopathological studies on leukocytes and various organs of patients with mannosidosis have demonstrated vacuolization, observed by light microscopy (Kjellman et al., 1969), and abnormality of lysosomes, observed by electron microscopy (Monus et al., 1977).

These findings and the difference in isozyme patterns of mannosidase observed in different organs (Poenau and Dreyfus, 1973) suggest that reported cases, including ours, were caused by $\alpha$-D-mannosidase deficiency in lysosomes (fractions A and B) but not in cytosolic fraction C (Philips et al., 1974; Opheim and Touster, 1978; Bischoff and Kornfeld, 1983).

The two patients with type 2 mannosidosis showed deficiency of isozymes A and $\mathbf{B}$ of mannosidase, encoded by the gene on chromosome 19. Type 1 mannosidosis, which shows early onset and results in death in the infantile period, is also caused by the deficiency of the fractions A and B (Beaudet, 1976). Studies are required why deficiencies of the same isozymes result in such different clinical manifestations and courses in type 1 and type 2 mannosidosis (Desnick et al., 1976).

\section{REFERENCES}

Beaudet, A.L. 1976. Disorders of glycoprotein degradation: Mannosidosis, fucosidosis, sialidosis, and aspartylglycosaminuria. In The Metabolic Basis of Inherited Disease, Stanbury, J.B., Wyngaarden, J.B., Fredrickson, D.S., Goldstein, J.L., and Brown, M.S., eds., McGraw-Hill Book Co., New York, pp. 788-802.

Bischoff, J, and Kornfeld, R. 1983. Evidence for an $\alpha$-D-mannosidase in endoplasmic reticulum of rat liver. J. Biol. Chem. 258: 7907-7910. 
Cheng, S., Malcolm, S., Pemble, S., and Winchester, B. 1986. Purification and comparison of the structures of human liver acidic $\alpha$-D-mannosidase A and B. Biochem. J. 233: 65-72.

Champion, M.J. and Shows, T.B. 1977. Mannosidosis: Assignment of the lysosomal $\alpha$-D-mannosidase B gene to chromosome 19 in man. Proc. Natl. Acad. Sci. USA. 74: 2968-2972.

Champion, M.J., Brown, J.A., and Shows, T.B. 1978. Assignment of cytoplasmic a-D-mannosidase $\left(\mathrm{MAN}_{\mathrm{A}}\right)$ and confirmation of mitochondrial isocitrate dehydrogenase (1DHM) to the q11-qter region of chromosome 15 in man. Cytogenet. Cell. Genet. 22: 498-502.

Desnick, R.J., Sharp, H.L., Grabowski, G.A., Brunning, R.D., Quie, P.G., Sung, J.H., Gorlin, R.J., and Ikonne, J.U. 1976. Mannosidosis: Clinical morphologic, immunologic, and biochemical studies. Pediatr. Res. 10: 985-996.

Doi, K., Asai, H., Ohya, Y., Sakai, K., Okada, S., and Kitani, T. 1982. A case report of mannosidosis. Audiol. Jpn. (in Japanese) 25: 349-350.

Furgason-Smith, M.A. and Aitken, D.A. 1978. Gene dosage: further information on regional position of the ABO : Np : AKI linkage group on chromosome 9. Cytogenet. Cell. Genet. 22: $449-451$.

Fluharty, A.L., Lassila, F.L., Porter, M.T., and Kihara, H. 1971. The electrophoretic separation of human galactosidase on cellulose acetate. Biochem. Med. 5: 158-164.

Hindman, J. and Cotlier, E. 1972. Glycosidases in normal human leukocytes and abnormalities in GM1-gangliosidosis. Clin. Chem. 18: 971-975.

Ichiki, S., Mitsudome, A., Okada, S., Nishimura, M., Yutaka, T., Oda, T., and Yamano, T. 1981. A case report of two siblings of mannosidosis-clinical and enzymatic studies on the first case in Japan. $J p n . J$. Pediatr. (in Japanese) 85: 1753-1762.

Ingram, P.H., Bruns, G.A.P., Regina, V.M., Eiseman, R.E., and Gerald, P.S. 1977. Expression of $\alpha$-D-mannosidase in man-hamster somatic cell hybrids. Biochem. Genet, 15: 455-476.

Kawai, H., Nishida, Y., Nishino, H., Inui, T., Saito, S., Takeda, M., Yoneda, K., Adachi, K., Takeda, E., and Miyao, M. 1986. Two sisters with mannosidosis: Clinical manifestation and pathological findings in the skeletal muscle. Jpn. J. Med. (in Japanese) 75: 638-648.

Kampine, J.P., Brady, R.O., Kanfer, J.N., Feld, M., and Sharipiro, D. 1966. Diagnosis of Gaucher's disease and Niemann-Pick disease with small samples of venous blood. Science 155: 86-88.

Kjellman, B., Gamstorp, I., Brun, A., Öckerman, P., and Palmgrem, B. 1969. Mannosidosis, a clinical and histopathologic study. J. Pediatr. 75: 366-373.

Monus, Z., Konyar, E., and Szabo, L. 1977. Histomorphologic and histochenical investigation in mannosidosis. Virchow Arch. B (Cell Pathol.) 26: 159.

Öckerman, P.A. 1967. A generalized storage disorder resembling Hurler's syndrome. Lancet 2: 239-241.

Opheim, D.J. and Touster, O. 1978. Lysosomal $\alpha$-D-mannosidase of rat liver: purification and comparison with the Golgi and cytosolic a-D-mannosidosis. J. Biol. Chem. 253: 1017-1023.

Philips, N.C., Robinson, D., and Winchester, B.G. 1974. Human liver $a$-D-mannosidase activity. Clin. Chim. Acta 55: 11-19.

Poenau, L. and Dreyfus, J.C. 1973. Electrophoretic heterogeneity of human $a$-D-mannosidase. Biochim. Biophys. Acta 303: 171-174.

Schafit-Zagardo, B., Devine, E.A., and Desnik, R.J. 1980. Electrophoretic separation of neutral and acid $\alpha$-glucosidase isozymes in human tissues. Biochim. Biophys. Acta 614: 459-465. 